\title{
Gray'in Muhasebe Değerleri Üzerine Ampirik Bir Değerlendirme (An Empiric Assesment on The Accounting Values of Gray)
}

\author{
Mehmet YÜCENURŞEN (iD) a Mustafa KARAKUŞ iD b \\ a Aksaray Üniversitesi, Ortaköy MYO, Finans, Bankacılık ve Sigortacılık Bölümü, Aksaray, Türkiye. yucenursen@hotmail.com \\ b İskenderun Teknik Üniversitesi, İskenderun Meslek Yüksekokulu, İskenderun, Türkiye. mustafa.karakus@iste.edu.tr
}

\begin{tabular}{|c|c|}
\hline MAKALE BİLGİSİ & ÖZET \\
\hline $\begin{array}{l}\text { Muhasebe Değerleri } \\
\text { Kültür } \\
\text { Kültür Boyutları }\end{array}$ & $\begin{array}{l}\text { Amaç - Bu çalışmada, Gray'in teorik olarak ileri sürdüğü muhasebe değerleri olan profesyonellik, } \\
\text { tekdüzelik, tutuculuk ve gizliliğe yönelik ampirik bir değerlendirme gerçekleştirmek amaçlanmıştır. } \\
\text { Araştırmanın, Türkçe literatürde Hofstede-Gray modeline yönelik ampirik bir değerlendirme } \\
\text { olmaması nedeniyle ilgili yazına katkı sağlayacağı düşünülmektedir. }\end{array}$ \\
\hline $\begin{array}{l}\text { Gönderilme Tarihi } 2 \text { Kasım } 2020 \\
\text { Revizyon Tarihi } 1 \text { Mart } 2021 \\
\text { Kabul Tarihi } 14 \text { Mart } 2021\end{array}$ & $\begin{array}{l}\text { Yöntem - Çalışmada Aksaray ilinde faaliyet gösteren Serbest Muhasebeci Mali Müşavirler (SMMM) } \\
\text { anakütle olarak belirlenmiş ve } 108 \text { muhasebe meslek mensubuna bir anket uygulaması } \\
\text { gerçekleştirilmiştir. Elde edilen verilerin analizinde, tanımlayıcı istatistikler ile açımlayıcı faktör } \\
\text { analizi ve keşfedici faktör analizi gerçekleştirilmiştir. }\end{array}$ \\
\hline
\end{tabular}

Bulgular - Elde edilen bulgular, Gray'in muhasebe değerleri modelinin kısmen desteklendiğini göstermektedir ancak tutuculuk değeri 'açıklama açısından tutuculuk' ve 'değerleme/ölçüm açısından tutuculuk' olarak iki ayrı faktöre yüklenmiştir.

Makale Kategorisi:

Araştırma Makalesi

Tartışma - Araştırmada kullanılan ölçeğin açıklanan toplam varyans değeri \%64,582 olduğundan dolayı henüz tanımlanmamış başka muhasebe değerlerinden söz edilebilir. Bu bağlamda, teorik temel yerine deneysel olarak hazırlanan veri toplama tekniği ile tanımlanmamış diğer muhasebe değerlerini tanımlamak mümkün olabilecektir.

\begin{tabular}{|c|c|}
\hline ARTICLE INFO & ABSTRACT \\
\hline $\begin{array}{l}\text { Accounting Values } \\
\text { Culture } \\
\text { Cultural Dimensions }\end{array}$ & $\begin{array}{l}\text { Purpose - In this study, it is aimed to perform an empirical evaluation of the accounting values that } \\
\text { Gray put forward theoretically, such as professionalism, uniformity, conservatism and } \\
\text { confidentiality. It is thought that the study will contribute to the related article since there is no } \\
\text { empirical evaluation of the Hofstede-Gray model in the Turkish literature. }\end{array}$ \\
\hline $\begin{array}{l}\text { Received } 2 \text { November } 2020 \\
\text { Revised } 1 \text { March } 2021 \\
\text { Accepted } 14 \text { March } 2021\end{array}$ & $\begin{array}{l}\text { Design/methodology/approach - In the study, Certified Public Accountants (CPA) operating in } \\
\text { Aksaray province were determined as the population and a questionnaire was applied to } 108 \\
\text { professional accountants operating in Aksaray. In the analysis of the obtained data, descriptive } \\
\text { statistics, exploratory factor analysis and confirmatory factor analysis were performed. }\end{array}$ \\
\hline \multirow{2}{*}{$\begin{array}{l}\text { Article Classification: } \\
\text { Research Article }\end{array}$} & $\begin{array}{l}\text { Findings - The findings show that Gray's accounting values model is partially supported, but the } \\
\text { conservative value was loaded on two separate factors as "conservative in terms of disclosure" and } \\
\text { "conservative in terms of valuation / measurement". }\end{array}$ \\
\hline & $\begin{array}{l}\text { Discussion - Since the total variance value of the scale used in the study is } 64.582 \% \text {, it can be } \\
\text { mentioned that there are other accounting values that have not been defined yet. In this context, it } \\
\text { will be possible to define other undefined accounting values with the data collection technique } \\
\text { prepared experimentally instead of the theoretical basis. }\end{array}$ \\
\hline
\end{tabular}




\section{Giriş}

Muhasebe; ekonomik sistem, kalkınmışlık seviyesi, kültür, sosyal çevre, eğitim vb. birçok faktörün etkisi altındadır. Söz konusu bu faktörler arasında kültür, muhasebe üzerinde en önemli ve en derin etkiye sahiptir (Keskin, Tutar \& Yazgan, 2020).

Gray'in 1988 yilında yayınlanan "Towards a Theory of Cultural Influence on the Development of Accounting Systems Internationally" isimli çalışması, kültürün muhasebe uygulamalarını etkileyebileceği görüşünü öne sürmesi açısından öncü bir çalışmadır. Gray (1988) bu çalışmasında, Hofstede tarafından geliştirilen kültür boyutlarını (1980) ve uluslararası muhasebe literatürünü bir araya getiren, dolayısıyla toplumsal ve muhasebe değerlerini birbirine bağlayan bir model önermiştir.

Bu çalışmada öncelikle Hofstede-Gray modeline ilişkin kavramsal çerçeve incelenmiş ve ilgili literatürdeki çalışmalar incelenmiştir. Devamında ise araştırma metodolojisine ilişkin olarak örneklem ve gerçekleştirilecek analizlere ait bilgiler yer almaktadır. Bu çalışmada, Gray'in Hofstede-Gray modeli çerçevesi için temel olan muhasebe-değer yapılarını incelenmektedir. Araştırma, Aksaray ilinde faaliyet gösteren muhasebe meslek mensuplarının algılarına dayanan ve Gray'in değer yapılarının varlığını test eden bir yaklaşıma dayanmaktadır. Bulgular ve analizler bölümünde ise gerçekleştirilen açımlayıcı ve doğrulayıcı faktör analizine ilişkin bilgiler verilmiş ve yorumlanmaya çalışılmıştır. Son olarak sonuç ve tartışmalar bölümünde araştırmada ulaşılan sonuç, araştırmanın sınırlamaları ve gelecekteki araştırmalar için öneriler sunulmaya çalışılmıştır.

Literatürde Hofstede-Gray modeli olarak alınan bu modeli inceleyen birçok teorik ve deneysel çalışma yürütülmüştür. Bu çalışmada ise, söz konusu modele ilişkin ampirik bir değerlendirme gerçekleştirilmesi amaçlanmıştır. Türkçe literatürde, Hofstede-Gray modeline yönelik ampirik bir değerlendirme olmaması nedeniyle bu çalışma gerçekleştirilmiştir.

\section{Kavramsal Çerçeve}

Gray (1988), oluşturduğu muhasebe değerlerine ilişkin çerçeveyi büyük ölçüde Hofstede'nin (1980) çalışmasına dayandırmıştır. Hofstede 1980 yılında yayınladığ 1 “Culture's Consequences, International Differences in Work-Related Value" isimli kitabı ile kültür alanında özellikle nicel araştırmaların önünü açmıştır. Hofstede'nin kültür modeli, kapsamı ve ulusal kültür boyutlarının çeşitliliği açılarından sosyal bilimlerde araştırmacılar tarafında sıkça başvurulan bir modeldir (Saylık, 2019).

Hofstede (1980), ulusal kültürün 4 boyuttan oluştuğunu ifade etmektedir: Güç mesafesi (power distance), belirsizlikten kaçınma (uncertainity avoidance), bireycilik-çoğulculuk (individualism-collectivism) ve erillikdişilik (masculinity-femininity).

- Güç mesafesi: Güç mesafesi boyutu, bir toplumun üyelerinin, kurum ve kuruluşlardaki gücün eşitsiz olarak dağıtıldığını kabul etme derecesini ifade etmektedir (Hofstede \& Bond, 1984). Bu durum, toplumun güçlü üyelerinin yanı sıra daha az güçlü üyelerin de davranışlarını etkileyen bir durumdur. Yüksek güç mesafesine sahip toplumun üyeleri, bütün üyelerin hiyerarşik düzene göre konumlanmasını herhangi bir gerekçeye bağlı olmaksızın kabul ederken, düşük güç mesafesine sahip toplumlarda ise toplumun üyeleri güç eşitliği için çabalarlar ve güç eşitsizliği için gerekçelendirme isterler (Hofstede \& Bond, 1984). Bu boyutun ele aldığı temel mesele, bir toplumun bireyler arasındaki eşitsizliği ele alma biçimidir (Soares, Farhangmehr \& Shoham, 2007). Bu durum, bireylerin kurum ve kuruluşları inşa etme yöntemlerini etkileyecektir.

- Belirsizlikten kaçınma: Belirsizlikten kaçınma boyutu, bir toplumun üyelerinin belirsizlikten rahatsızlık duyma derecelerini ifade etmektedir (Hofstede \& Usunier, 2003: 141). Söz konusu rahatsılık duygusu, bireyleri kesinlik vaat eden inançlara ve uyumu bozmayan kurum ve kuruluşları sürdürmeye yöneltecektir. Güçlü bir belirsizlikten kaçınmaya sahip bir toplum, katı inanç ve davranış kalıplarını koruyacak ve farklı fikirlere karşı hoşgörüsüz olacak; aksi bir durumda ise toplum, uygulamaların ilkelerden daha önemli olduğu rahat bir atmosfer inşa edecektir (Hofstede \& Usunier, 2003: 141). Bu boyutun ele aldığı temel mesele, zamanın doğrusal olduğu ve geleceğin bilinmezliğine verilecek tepkidir (Merritt, 2000). Güç mesafesi boyutu gibi belirsizlikten kaçınma boyutu da bireylerin kurum ve kuruluşları inşa etme yöntemlerini etkileyecektir. 
- Bireycilik-Çoğulculuk: Bireycilik, bireylerin yalnızca kendilerine ve ailelerine bakmalarının beklendiği ve bireyin toplum ile ilişkisinin zayıf olduğunu, zıttı olan çoğulculuk ise bireylerin akrabalarının, klanlarının veya diğer grupların sorgusuz sualsiz sadakat karşılığında onlara bakmasını bekleyebilecekleri birbirine sıkı sıkıya bağlı bir sosyal çerçeve tercihini ifade eder (Hofstede, 2011). Bu boyutun ele aldığı temel mesele, bir toplumun bireyler arasında sürdürdüğü karşılıklı bağımlılığın derecesidir (Blodgett, Bakir \& Rose, 2008). Başka bir ifade ile kişinin benlik algısı ile ilgilidir: 'Ben' veya 'biz'.

- Erillik-Dişilik: Erillik, toplumda başarı, kahramanlık, iddialı olmak ve maddi başarı için tercih anlamına gelirken; tersi olan dişilik ise ilişkiler, alçakgönüllülük, zayıflara değer verme ve yaşam kalitesi için bir tercih anlamına gelir (Hofstede \& Bond, 1984). Bu boyutun ele aldığ 1 bu temel mesele, bir toplumun toplumsal rolleri cinsiyetlere tahsis etme biçimidir. Bazı toplumlar, cinsiyetler arasında maksimum sosyal farklılaşma için çabalar (Mooij \& Hofstede, 2010). Bu durumda norm, erkeklere daha dışa dönük, iddialı roller, kadınlara ise şefkatli, besleyici roller verilmesidir. Bazı toplumlar ise cinsiyetler arasında asgari sosyal farklılaşma için çabalar (Huettinger, 2008). Bu durum, bazı kadınların isterlerse iddialı roller alabilecekleri, özellikle de bazı erkeklerin isterlerse ilişki odaklı, mütevazı, şefkatli roller alabilecekleri anlamına gelir. Asgari sosyal farklılaşmaya sahip toplumlar, zıtları olan maksimum sosyal farklılaşma toplumları ile karşılaştırıldığında, kurumlarına özenli, yaşam kalitesi odaklı bir zihniyetle nüfuz edeceklerdir. Bu tür toplumlar, tüm üyelerine -en zayıflarına bile- değer vermenin hem erkekler hem de kadınlar için önemli bir hedef olduğu 'refah toplumu'na evrilmiştir.

Gray'in (1988), muhasebe uygulamalarının kültürden etkilenebileceği argümanına ilişkin çerçeve Şekil 1'de belirtilmiştir. Gray (1988), Hofstede'nin (1980) modelini geliştirerek kültür ve muhasebe değerleri arasındaki ilişkiyi açılayan bir çerçeve oluşturmuştur.

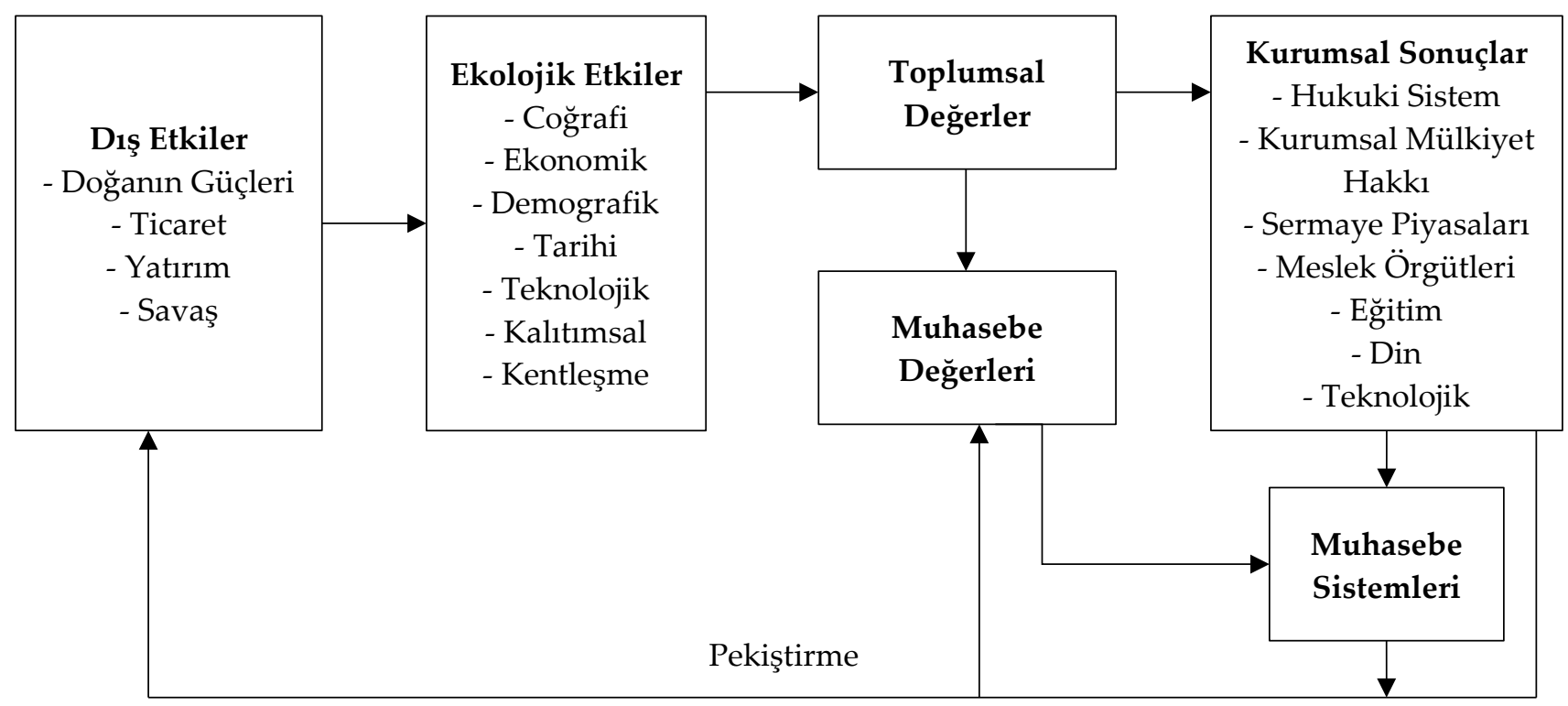

Kaynak: Gray, 1988.

Şekil 1. Kültürr, Toplumsal Değerler ve Alt-Kültür Olarak Muhasebe

Gray'in (1988) oluşturduğu çerçevede, dış etkilerin fiziksel çevreyi etkilediği görülmektedir. Örneğin küreselleşme ve savaş, toplumsal düzeydeki fiziksel veya ekolojik çevreleri etkiler. Bu dış güçler; birey, grup veya toplum tarafından kontrol edilemez ve bir toplumun gelişimini büyük ölçüde etkileyebilir. Gray (1988), toplumsal değerlerin muhasebe değerlerini ve uygulamalarını doğrudan ve dolaylı etkilediği ilişki ve muhasebe değerleri ve uygulamaları arasında doğrudan bir ilişki belirtmektedir.

Gray (1988), muhasebenin toplumsal değerlerin çıktısı olduğunu belirtmektedir. Bu nedenle, muhasebe toplumsal kültür içerisinde bir alt-kültürdür (sub-culture). Bu bağlamda, Gray (1988) Hofstede'nin kültür boyutlarını temel alarak dört muhasebe değeri oluşturmuştur: profesyonellik/statükoculuk (professionalism versus statutory control), tekdüzelik/esneklik (uniformity versus flexibility), tutuculuk/iyimserlik (conservatism versus optimism), gizlilik/şeffaflık (secrecy versus transparency). 
- Profesyonellik/Statükoculuk: Profesyonellik, muhasebe uygulamalarına ilişkin bireysel mesleki muhakemenin kullanılması ve mesleki öz-düzenlemenin sürdürülmesi iken statükoculuk ise yasal gerekliliklere ve yasal kontrole uyarak muhasebe sisteminin oluşturulmasıdır (Gray, 1988). Bu değer, bir toplumun muhasebe kuralları ve düzenlemelerinde otoritenin önemini vurgulamaktadır (Khlif, 2016).

- Tekdüzelik/Esneklik: Bu değer, şirketler arasında tek tip muhasebe uygulamalarının uygulanması ve bu tür uygulamaların zaman içinde tutarlı bir şekilde kullanılması tercihini ifade eder (Gray, 1988). Bu değer, bir toplumun muhasebe kuralları ve düzenlemelerinde uygulamanın önemini vurgulamaktadır (Tsakumis, 2007).

- Tutuculuk/İyimserlik: İyimserlik bir toplumun daha iyimser, 'laissez-faire (bırakınız yapsınlar)' ve risk alma yaklaşımını benimsemesini, tutuculuk ise gelecekteki olayların belirsizliğiyle başa çıkmak için ölçüme ihtiyatlı bir yaklaşım tercih etmesini ifade eder (Gray, 1988). Bu değer, bir toplumun muhasebe kuralları ve düzenlemelerinde değerleme/ölçümün önemini vurgulamaktadır (Chanchani \& Willett, 2004). Muhasebe kuralları ve düzenlemeleri, varlıkların ve şirket karlılığının ölçülmesi ve raporlanması için bazı yöntem ve politikaları içerir. Benzer nitelikteki muhasebe uygulamaları, farklı ihtiyat düzeylerine bağlı olarak ülkeler arasında değişiklik gösterebilmektedir. Bu muhasebe değeri, ülke düzeyinde ihtiyat düzeyindeki farklılıkları vurgulamaktadır.

- Gizlilik/Şeffaflık: Bu değer, bir toplumun gizliliği tercih etmesi ve işletme hakkındaki bilgilerin daha şeffaf, açık ve halka açık bir şekilde değil, sadece işletme yönetimi ve finansmanı ile yakından ilgili olanlarla sınırlandırılması olarak ifade edilebilir (Gray, 1988). Bu değer, bir toplumun muhasebe kuralları ve düzenlemelerinde aydınlatmanın önemini vurgulamaktadır (Borker, 2013).

Gray (1988), oluşturduğu muhasebe değerleri ile Hofstede'nin (1980) kültür boyutları arasındaki ilişkiyi zayıf, orta ve güçlü olmak üzere üç derecede belirtmiştir. Bu bağlamda, Gray'in (1988) muhasebe değerleri ile Hofstede'nin (1980) kültür boyutları arasındaki ilişki Tablo 1'de sunulmuştur.

Tablo 1. Muhasebe Değerleri ve Kültür Boyutları Arasındaki İlişki

\begin{tabular}{|c|c|c|c|c|c|}
\hline Muhasebe Değeri & $\begin{array}{c}\text { Ilişkinin } \\
\text { Derecesi }\end{array}$ & $\begin{array}{c}\text { Güç } \\
\text { Mesafesi }\end{array}$ & $\begin{array}{c}\text { Belirsizlikten } \\
\text { Kaçınma }\end{array}$ & $\begin{array}{c}\text { Bireycilik- } \\
\text { Çoğulculuk }\end{array}$ & $\begin{array}{c}\text { Erillik- } \\
\text { Dişilik }\end{array}$ \\
\hline \multirow{3}{*}{ Profesyonellik/Statükoculuk } & Zayıf & & & & Pozitif \\
\cline { 2 - 6 } & Orta & Negatif & & & \\
\cline { 2 - 6 } & Güçlü & & Negatif & Pozitif & \\
\hline \multirow{3}{*}{ Tekdüzelik/Esneklik } & Zayıf & & & & \\
\cline { 2 - 6 } & Orta & Pozitif & & & \\
\cline { 2 - 6 } & Güçlü & & Pozitif & Negatif & \\
\hline \multirow{3}{*}{ Tutuculuk/İyimserlik } & Zayıff & & & & \\
\cline { 2 - 6 } & Orta & & & Negatif & Negatif \\
\cline { 2 - 6 } & Güçlü & & Pozitif & & \\
\hline \multirow{3}{*}{ Gizlilik/Şeffaflık } & Zayıff & & & & \\
\cline { 2 - 6 } & Orta & & & Negatif \\
\cline { 2 - 6 } & Güçlü & Pozitif & Pozitif & Negatif & \\
\hline
\end{tabular}

Boş kutucuklar ilişki olmadığını göstermektedir.

Kaynak: Rodriguez, 2009: 14.

Tablo 1 incelendiğinde, güçlü bir şekilde belirsizlikten kaçınan ve çoğulcu bir toplumun statükocu yapıda olduğu söylenebilir. Aynı şekilde belirsizlikten kaçınan, güç mesafesi yüksek ve çoğulcu bir toplumun gizliliği benimsediği söylenebilir.

\section{Literatür Taraması}

Salter ve Niswander (1995), Gray (1988) tarafından geliştirilen ve muhasebe değerlerini Hofstede'nin (1980) kültürel yapılarıyla ilişkilendiren teoriyi test etmeye yönelik bir araştıma gerçekleştirmişlerdir. Araştırmada yirmi dokuz ülkeden elde edilen verilere dayanılarak, Gray'in (1988) modelinin istatistiksel olarak önemli bir açıklama gücü olmasına rağmen, finansal raporlama uygulamalarını açıklamada en iyisi olduğu ve mevcut mesleki ve düzenleyici yapıları kültürel bir temelden açıklamada görece zayıf olduğu tespit edilmiştir. Benzer bir çalışma Sudarwan ve Fogarty (1996) tarafından gerçekleştirilmiştir. Çalışma sonucuna göre, Tablo 1'de 
belirtilen muhasebe değerleri ile kültür boyutları arasındaki 13 ilişkiden 9 tanesi desteklenirken 4 tanesi desteklenmemiştir. Noravesh, Dilami ve Bazaz (2007) tarafından yürütülen çalı̧̧mada ise söz konusu 13 ilişkiden 8 tanesini desteklenmiş, 4 tanesi desteklenmemiştir.

Schultz ve Lopez (2001), muhasebecilerin benzer finansal raporlama standartların yorumlanması ve uygulanmasında kültürün etkisini ölçmeye yönelik olarak Fransa, Almanya ve ABD'de bir çalışma gerçekleştirmişlerdir. Yüksek derecede belirsizlikten kaçınan ülkelerin (Fransa ve Almanya), düşük derecede belirsizlikten kaçınan ülkeye (ABD) göre tutuculuğunun yüksek olduğu belirlenmiştir.

Chanchani ve Willett (2004), Hofstede-Gray modelini test etmek amaciyla Yeni Zelanda ve Hindistan'da 1604 katılımcı bir çalışma ile gerçekleştirmişlerdir. Bu amaca yönelik olarak "muhasebe değerleri anketi" oluşturulmuş ve özdeğerleri 1'in üstünde olan ve toplam varyansın \%49'unu açılayan 5 faktöre ulaşılmıştır.

Doupnik ve Riccio (2006), tutuculuk/iyimserlik ve gizlilik/şeffaflık değerleri açısından muhasebecilerin finansal raporlama standartlarını yorumlaması ve uygulamasında kültürün etkisini ölçmeye yönelik olarak Brezilya ve ABD'de bir çalışma yürütmüşlerdir. Çalışma sonucunda, gelir artışlarını tanıma ile tutuculuk hipotezi arasında güçlü bir ilişki ve finansal bilgilerin açıklanması ile gizlilik hipotezi arasında güçlü bir ilişki tespit edilmiştir.

Tsakumis (2007), ulusal kültürün muhasebecilerin muhasebe kurallarını uygulamaları üzerindeki etkisini incelemeyi amaçlayan bir çalışma gerçekleştirmiştir. Gray'in (1988) çerçevesini temel alan bu çalışma, Yunanistan ve ABD'de gerçekleştirilmiş olup, Yunan muhasebecilerin ABD muhasebecilerinden koşullu borçları ve varlıkları raporlamasının daha olası olacağını varsaymaktadır $\left(\mathrm{H}_{1}\right)$. Ayrıca, Yunan muhasebecilerin ABD muhasebecilerinden hem koşullu varlıkların hem de yükümlülüklerin varlığını ifşa etme olasılığının daha düşük olacağı varsayılmaktadır $\left(\mathrm{H}_{2}\right)$. Çalışma sonucuna göre $\mathrm{H}_{1}$ desteklenmemiş, $\mathrm{H}_{2}$ desteklenmiştir.

Salter ve Lewis (2011), on beş ülkede Hofstede-Gray modeli çerçevesinde gerçekleştirdikleri çalışmalarında bireyciliğin, ülkeler arasındaki gelir ölçümü uygulamalarındaki farklılıklarla anlamlı ve olumlu bir şekilde ilişkili olduğunu göstermektedir.

Albuquerque, Almeida ve Quirós (2011), Hofstede-Gray modeli çerçevesinde Portekiz'in konumunu incelemeyi amaçlayan bir çalışma gerçekleştirmişlerdir. Çalışma sonucunda, statükoculuk ve tekdüzelik değerlerinin güçlü, gizlilik ve tutuculuk değerlerinin ise kabul edilebilir seviyede olduğu tespit edilmiştir.

Bekci ve Bitlisli (2012), Hofstede-Gray modeli çerçevesinde Isparta ilinde faaliyet gösteren muhasebe meslek mensupları açısından muhasebe değerlerinin hangi konumda olduğunu belirlemeyi amaçlayan bir çalışma gerçekleştirmişlerdir. Benzer bir çalışma yürüten Durmuş ve Güneş (2017) ise katılımcıların profesyonellikten yana, tekdüzeliği ve tutuculuğu savunan buna karşın şeffaflık ilkesini destekleyen düşüncelerde olduklarını tespit etmiştir.

Perera, Cummings ve Chua (2012), Hofstede-Gray modeli çerçevesinde Samoa ve Yeni Zelanda'da muhasebe değerlerine yönelik gerçekleştirdikleri çalışmalarında; Samoa'da düşük seviyede profesyonellik, Yeni Zelanda'da ise yüksek seviyede profesyonellik tespit edilmiştir.

Kestane ve Ağca (2017) tarafından çalışmada ise Hofstede-Gray modeli uyarınca UFRS'yi benimseyen ve uygulayan ülkeler içinde Türkiye'nin konumunu belirlemek amaçlanmıştır. Araştırmanın sonucuna göre Türkiye'nin; güç mesafesi ve bireysellik-çoğulculuk değeri açısından göreli olarak Anglosakson ülkelerine, erillik-dişilik değeri bakımından Anglosakson ve kıta Avrupası ülkelerine, belirsizlikten kaçınma değeri bakımından ise kıta Avrupası ve Güney Amerikan ülkelerine yakın olduğu sonucuna ulaşılmıştır.

Keskin, Tutar ve Yazgan (2020) ise Türkiye, Nijerya, Letonya ve İngiltere'de faaliyet gösteren dört denetim şirketinin yayınladıkları şeffaflık raporlarını Hofstede-Gray modeline göre kültürel farklılıklarını inceleyen bir çalışma gerçekleştirmişlerdir. Araştırma sonucunda, yerel kültürel özelliklerin şeffaflık raporlarında farklılık yarattığ 1 tespit edilmiştir. 


\section{Yöntem}

\subsection{Araştırmanın Amacı ve Önemi}

Bu çalışmada, Gray'in teorik olarak ileri sürdüğü muhasebe değerleri olan profesyonellik, tekdüzelik, tutuculuk ve gizliliğe yönelik ampirik bir değerlendirme gerçekleştirmek amaçlanmaktadır. Araştırmanın, Türkçe literatürde Hofstede-Gray modeline yönelik ampirik bir değerlendirme olmaması nedeniyle ilgili yazına katkı sağlayacağı düşünülmektedir.

\subsection{Evren ve Örneklem}

Araştırmada, Hofstede-Gray modeline yönelik ampirik bir değerlendirme yapmak amacıyla kuramsal bağlama uygun katılımcılardan veri elde edilmesi planlanmıştır. Bu doğrultuda, Aksaray ilinde faaliyet gösteren Serbest Muhasebeci Mali Müşavirler (SMMM) ana kütle olarak belirlenmiştir. Aksaray SMMM odasında alınan bilgilere göre, Aksaray ilinde odaya kayıtlı toplam 194 SMMM bulunmakta olup, bunların 123 aktif olarak çalışmaktadır.

Bu bağlamda, söz konusu anakütleden $\% 95$ güven düzeyinde ve $\% 5$ hata payı ile örneklem büyüklügünün asgari 93 olması gerektiği hesaplanmıştır (https://www.surveysystem.com/sscalc.htm). Nicel olarak tasarlanan bu araştırmanın birincil verileri, katılımcılardan anket yolu ile elde edilmiştir. Verilerin toplanmasında basit tesadüfi yöntem tercih edilmiştir.

\subsection{Veri Toplama Araçları}

Araştırma için hazırlanan anket formu iki bölümden oluşmaktadır. Anket formunun birinci kısmı katılımcılara ilişkin demografik bilgiler; ikinci bölümü ise Chanchani ve Willett (2004) tarafından geliştirilen ve Karabınar (2005) tarafından Türkçe'ye uyarlanan Muhasebe Değerleri Anketi (Accounting Value SurveyAVS) kapsamındaki ifadelerden oluşmaktadır. Ankette yer alan bütün değişkenler için 5'li Likert tipi ölçek kullanılmıştır. Ölçek maddeleri 'tekdüzelik' (2., 6., 10., 14. ifadeler), 'profesyonellik' (4., 8., 12., 16. ifadeler), 'gizlilik' (3., 7., 11., 15. ifadeler) ve 'tutuculuk' (1., 5., 9., 13. ifadeler) boyutlarıyla değerlendirilmiştir. Ölçek maddelerinin tümü ekte sunulmuştur.

Bu çalışma için etik komite onayı T.C. Aksaray Üniversitesi İnsan Araştırmaları Etik Kurulu'ndan 21.10.2020 tarih ve 2020/09-14 sayılı karar ile alınmıştır. Anket uygulaması, 22.10.2020 - 27.10.2020 tarihleri arasında gerçekleştirilmiştir.

\subsection{Verilerin Analizi}

Çalışmada ölçekten elde edilen verilerin istatistiki analizi için SPSS ve AMOS paket programları kullanılmıştır. Ölçeğin iç tutarlılığı için Cronbach Alfa katsayısı hesaplanmıştır. Araştırmada kullanılan ölçeğin yapı geçerliliğini tespit etmek için sırasıyla açımlayıcı ve doğrulayıı faktör analizi gerçekleştirilmiştir.

Katılımcılardan elde edilen anket formları incelendiğinde, 4 adet anket hatalı ve eksik veri giriş nedeniyle elenmiştir ve 108 adet anketin analize uygun olduğu görülmüştür. Bu araştırmanın kısıtı, araştırma örneğinin Aksaray şehir merkezinde faaliyet gösteren SMMM'ler ile sınırlandırılmasıdır.

\section{Bulgular}

Araştırma kapsamında katılımcılar ile ilgili sosyo-demografik özellikler Tablo 2' de sunulmuştur.

Tablo 2. Katılımcılar ile İlgili Sosyo-Demografik Özellikler

\begin{tabular}{|c|c|c|c|}
\hline Değişken & Kategori & Frekans & Yüzde \\
\hline \multirow{2}{*}{ Cinsiyet } & Erkek & 89 & 82,41 \\
\cline { 2 - 4 } & Kadın & 19 & 17,59 \\
\hline \multirow{2}{*}{ Yaş } & $25-40$ & 54 & 50,00 \\
\cline { 2 - 4 } & $41-60$ & 54 & 50,00 \\
\hline \multirow{4}{*}{ Eğitim Durumu } & Lise & 4 & 3,70 \\
\cline { 2 - 4 } & Önlisans & 3 & 2,78 \\
\cline { 2 - 4 } & Lisans & 87 & 80,56 \\
\cline { 2 - 4 } & Lisansüstü & 14 & 12,96 \\
\hline
\end{tabular}


M. Yücenurşen - M. Karakuş 13/1 (2021) 481-492

\begin{tabular}{|c|c|c|c|}
\hline \multirow{4}{*}{ Mesleki Tecrübe } & $1-5$ y1 & 4 & 3,7 \\
\cline { 2 - 4 } & $6-10$ yıl & 16 & 14,82 \\
\cline { 2 - 4 } & $11-15$ yıl & 32 & 29,63 \\
\cline { 2 - 4 } & 16 ve üzeri & 56 & 51,85 \\
\hline
\end{tabular}

Tablo 2 incelendiğinde araştırma kapsamında yer alan katılımcıların \%82,41'inin erkek ve \%17,59'unun kadın olduğu tespit edilmiştir. Aynı zamanda katılımcıların \%80,56’sının lisans seviyesinde eğitim gördükleri belirlenmiştir. Bunun yanı sıra, katılımcıların yarısından fazlasının $(\% 51,85)$ mesleki tecrübesinin 16 yıl ve üzeri olduğu tespit edilmiştir.

Tablo 3. Araştırmada Kullanılan Ölçeğe İlişkin Tanımlayıcı İstatistikler

\begin{tabular}{|c|c|c|c|c|c|}
\hline Boyutlar & Sorular & Ortalama & Standart Sapma & Çarpıklık & Basıklık \\
\hline \multirow{4}{*}{ Tekdüzelik } & MD2 & \multirow{4}{*}{3,5625} & \multirow{4}{*}{,85593 } & \multirow{4}{*}{,- 785} & \multirow{4}{*}{,711 } \\
\hline & MD6 & & & & \\
\hline & MD10 & & & & \\
\hline & MD14 & & & & \\
\hline \multirow{4}{*}{ Profesyonellik } & MD4 & \multirow{4}{*}{3,4954} & \multirow{4}{*}{ 83930 } & \multirow{4}{*}{,- 651} & \multirow{4}{*}{ 670 } \\
\hline & MD8 & & & & \\
\hline & MD12 & & & & \\
\hline & MD16 & & & & \\
\hline \multirow{4}{*}{ Gizlilik } & MD3 & \multirow{4}{*}{3,7083} & \multirow{4}{*}{,75078 } & \multirow{4}{*}{$-1,577$} & \multirow{4}{*}{1,879} \\
\hline & MD7 & & & & \\
\hline & MD11 & & & & \\
\hline & MD15 & & & & \\
\hline \multirow{4}{*}{ Tutuculuk } & MD1 & \multirow{4}{*}{3,1227} & \multirow{4}{*}{ 65165 } & \multirow{4}{*}{,- 893} & \multirow{4}{*}{1,630} \\
\hline & MD5 & & & & \\
\hline & MD9 & & & & \\
\hline & MD13 & & & & \\
\hline
\end{tabular}

Tablo 3 incelendiğinde çarpıklık ve basıklık değerlerinin +/- 2 sınırları içerisinde olduğu belirlenmiştir. Bu durum araştırmada kullanılan ölçeğin normal dağılım varsayımını sağladığını ifade etmektedir (Demir, Saatçioğlu \& İmrol, 2016).

Araştırmada kullanılan ölçeğin yapısal geçerliliğini test etmek amacıyla sırasıyla açımlayıcı faktör analizi ve doğrulayıcı faktör analizi gerçekleştirilmiştir. Faktör rotasyonu Varimax yöntemi ile gerçekleştirilmiştir. Açımlayıcı faktör analizi sonuçları Tablo 4'te gösterilmektedir.

Tablo 4. Araştırmada Kullanılan Ölçeğe İlişkin Açımlayıcı Faktör Analizi Sonuçları

\begin{tabular}{|c|c|c|c|c|c|}
\hline \multirow[b]{2}{*}{ Sorular } & \multicolumn{5}{|c|}{ Faktörler } \\
\hline & Tekdüzelik & Profesyonellik & Gizlilik & $\begin{array}{r}\text { Tutuculuk } \\
\text { (Açıklama) }\end{array}$ & $\begin{array}{c}\text { Tutuculuk } \\
\text { (Değerleme/Ölçüm) }\end{array}$ \\
\hline MD6 & ,733 & & & & \\
\hline MD14 & ,730 & & & & \\
\hline MD2 & 664 & & & & \\
\hline MD10 & ,566 & & & & \\
\hline MD9 & 431 & & & & \\
\hline MD12 & & 840 & & & \\
\hline MD8 & & ,704 & & & \\
\hline MD16 & & 612 & & & \\
\hline MD3 & & & ,756 & & \\
\hline MD7 & & & 613 & & \\
\hline MD11 & & & ,591 & & \\
\hline MD5 & & & & ,739 & \\
\hline MD15 & & & & 697 & \\
\hline
\end{tabular}




\begin{tabular}{|l|l|l|l|l|}
\hline \multicolumn{1}{|c|}{ MD4 } & & &, 578 & \\
\hline \multicolumn{1}{|c|}{ MD1 } & & & \\
\hline \multicolumn{1}{|c|}{ MD13 } & & & \\
\hline Cronbach's Alpha &, 739 & & \\
\hline Total Variance Explained & $\mathbf{6 4 , 5 8 2}$ & & \\
\hline KMO &, 750 & & \\
\hline$P$ &, 000 & & \\
\hline
\end{tabular}

Faktör analizi sonuçlarına göre ölçeğe ilişkin KMO değeri ,750 ve Barlett's test sonucu ise sig. p<0,01 olduğu belirlenmiştir. Bu durum kullanılan veri setinin faktör analizi yapmaya uygun olduğunu göstermektedir. Ölçeğin güvenirlik katsayısı (Cronbach's Alpha) 0,739'dur. Aynı zamanda araştırmada kullanılan ölçeğin açıklanan toplam varyans değer ise \%64,582 olarak belirlenmiştir. Analizde madde faktör yüklerinin 0,40 'dan düşük olmaması beklenmiştir.

Gray'in (1988) ortaya koyduğu model temel alındığında açımlayıcı faktör analizi, her biri muhasebe değeriyle ilişkili dört faktörü ortaya çıkarmalıdır. Ortaya konulan model ampirik olarak anlamlı ve muhasebe değerlerini temsil ediyorsa, verilerin alt kümeleri için aynı modelin ortaya çıkması gerekir. Tablo 4 ve Şekil 2 incelendiğinde özdeğerleri 1'in üstünde olan ve toplam varyansın \%64,582'sini açıklayan 5 faktöre ulaşıldığ1 görülecektir. Şekil 2'de, özdeğerin grafik olarak gösterilmesini sağlayan yamaç birikinti grafiği sunulmuştur. Buna göre, grafikte çizgi yatay şekil aldığ 1 noktaya (dirsek (elbow)) kadar olan faktörler elde edilecek maksimum faktör sayısı olarak kabul edilir. Bu bağlamda, açımlayıcı faktör analizi sonuçları Gray'in (1988) modelini kısmen desteklemektedir ancak tutuculuk değerinin açıklama açısından tutuculuk ve değerleme/ölçüm açısından tutuculuk olarak iki ayrı faktöre yüklenmiştir.

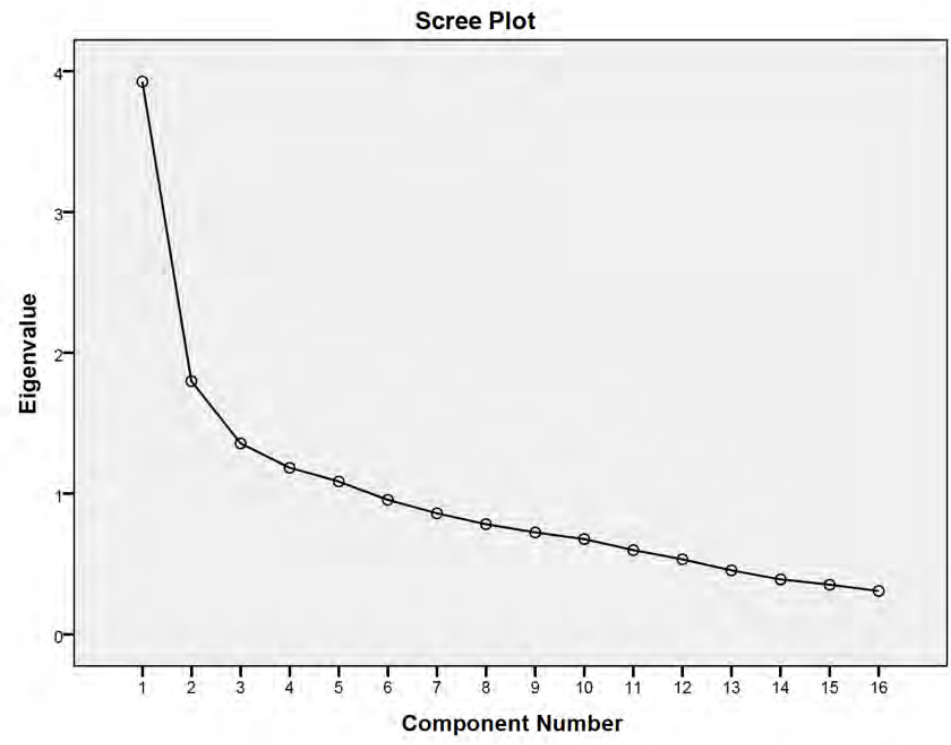

Şekil 2. Yamaç Birikinti Grafiği (Scree Plot)

Araştırmada gerçekleştirilen açımlayıcı faktör analizi sonuçlarına göre elde edilen faktör yapısı doğrulayıcı faktör analizi ile test edilmiştir. Doğrulayıcı faktör analizi ile 5 boyutlu bir yapı tespit edilmeye çalışılmıştır. Aynı zamanda ölçekte yer alan ifadelerin standardize edilmiş regresyon yüklerinin 0,50'den düşük olmaması istenmiştir. Bu bağlamda, gerçekleştirilen analizde bazı ifadelerin standardize edilmiş regresyon yüklerinin 0,50'den düşük olduğu görülmüş ve sırası ile MD3 ve MD5 maddeleri analizden çıkarılarak analiz tekrarlanmıştır. Bu bağlamda, doğrulayıcı faktör analizi sonuçları Şekil 3'te sunulmaktadır. 


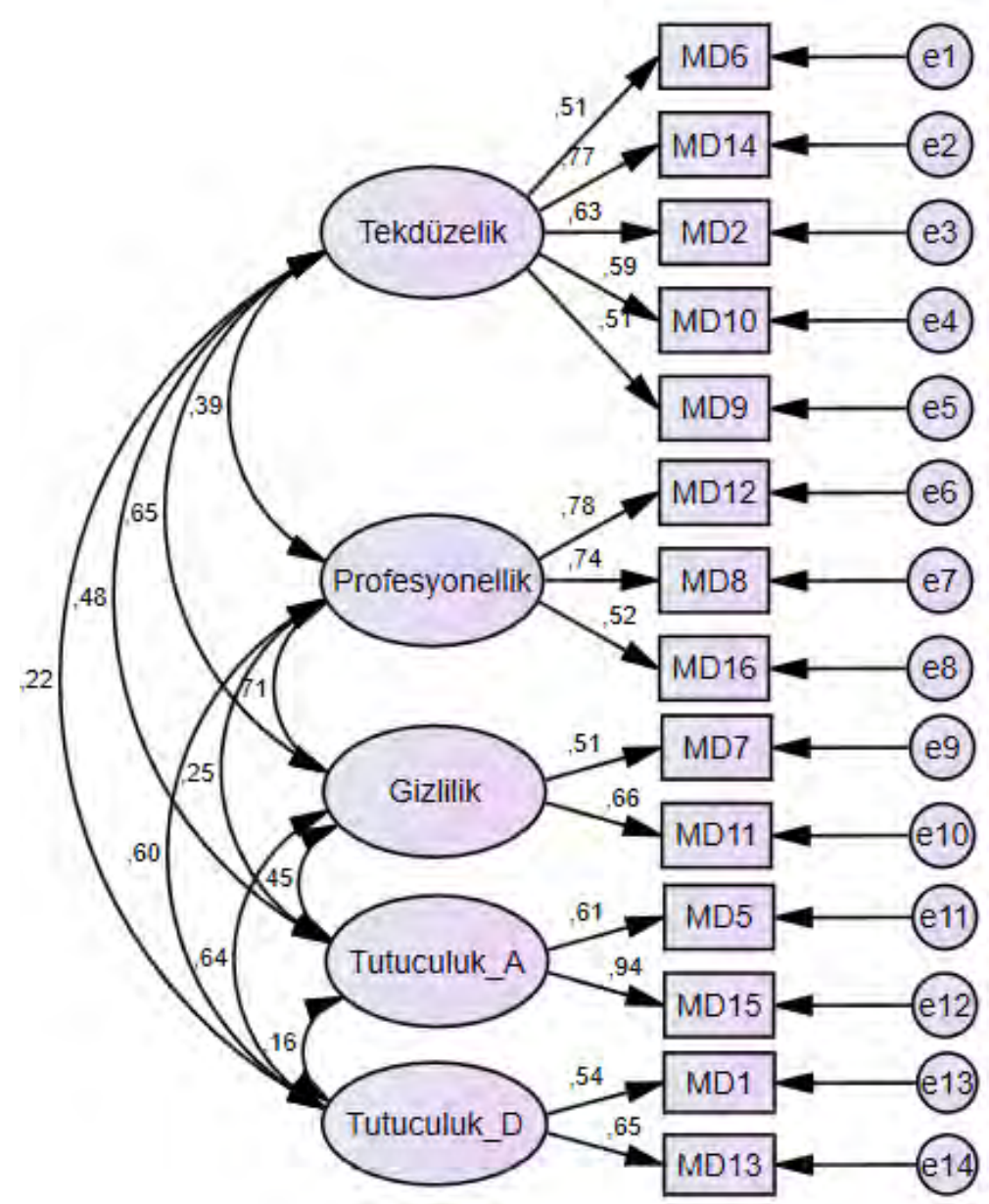

Şekil 3.Doğrulayıcı Faktör Analizi Sonuçları

Modelde indekslerin değerlerinin gerekli ölçütleri sağladığı gözlenmiştir. Model uyumuna ilişkin CMIN/DF, RMR, CFI, IFI, TLI, RMSEA değerleri referans alınmıştır (Yaşlığlu, 2017). Araştırma modeline ilişkin referans değerleri ve uyum indeksi sonuçları Tablo 5 'te verilmektedir.

Tablo 5. Modele İlişkin Uyum İndeksi Sonuçları

\begin{tabular}{|l|c|c|}
\hline İndeksler & Referans Değeri & İndeks Değerleri \\
\hline CMIN/DF & $0<\mathrm{x} 2 / \mathrm{sd} \leq 5$ & 1,027 \\
\hline GFI & $\geq, 90$ & 0,919 \\
\hline CFI & $\geq, 92$ & 0,993 \\
\hline TLI & $\geq, 92$ & 0,990 \\
\hline RMSEA & $\leq, 08$ & 0,016 \\
\hline
\end{tabular}

Tablo 5 incelendiğinde ölçeğin gerekli uyum indeksi ölçütlerinin sağlandığı görülmektedir. Şekil 2 ve Tablo 5 'de yer alan bulgular doğrultusunda ölçekteki 14 ifadenin faktör yapısına ve analize uygun olduğu ve elde edilen 14 maddeli ölçeğin yapı geçerliliğini sağladığı belirlenmiştir. Bu bağlamda, gerçekleştirilen analizlerden elde edilen tüm bulgular belirlenen beş boyutlu yapının doğrulandığını göstermektedir.

\section{Sonuç ve Tartışma}

Son yıllarda küreselleşmenin etkisiyle muhasebe bilgi kullanıcılarının, farklı ülkelerdeki farklı muhasebe uygulamaları sonucu ortaya çıkan farklı finansal tabloları analiz ve yorumlama açısından karşılaştıkları güçlük ve zorluklar; harmonizasyon ve yakınsama çabalarının artmasına neden olmuştur. Bu durumda, kültür-muhasebe ilişkisini inceleyen çalışmalar artış göstermiştir.

Muhasebe-kültür alanına ilişkin literatür incelendiğinde, Gray'in (1988) Hofstede'nin kültür modelini temel alarak (1980) ortaya koyduğu çalışmanın öncü bir çalışma olduğu görülmektedir. Gray (1988), toplumsal değerlerin muhasebe değerlerini etkilediği belirtmiş ve profesyonellik/statükoculuk, tekdüzelik/esneklik, 
tutuculuk/iyimserlik, gizlilik/şeffaflık olmak üzere dört adet muhasebe değeri oluşturmuştur. Gray'in çalışması öz itibari ile "a priori" bir çalışmadır.

Bu çalışmada, Gray'in (1988) oluşturduğu muhasebe değerleri ampirik olarak değerlendirilmeye çalışılmıştır. Çalışmada, Gray'in (1988) dört muhasebe değerinin her birini temsil eden dört boyutu ölçmeyi amaçlayan muhasebe değerleri anketi kullanılmıştır. Anketten elde edilen verilerin analizinde, açımlayıcı ve doğrulayıcı faktör analizleri gerçekleştirilmiştir. Söz konusu analizler sonucunda, Gray'in (1988) modelinin kısmen desteklendiği, başka bir ifade ile tekdüzelik, profesyonellik ve gizlilik boyutlarının tek boyuta, tutuculuk boyutunun ise açıklama açısından tutuculuk ve değerleme/ölçüm açısından tutuculuk olarak iki alt boyuta ayrılmış olduğu görülmektedir.

Araştırma sonuçları yorumlanırken dikkate alınması gereken bazı sınırlılıklardan bahsetmek mümkündür. Gray'in (1988) ortaya koyduğu model "a priori” bir modeldir. Bu bağlamda, araştırmada kullanılan ölçeği oluşturan ifadelerin deneysel olmaktan ziyade teorik temellendirmeye bağlı kalınarak şekillendirildiği söylenebilir.

Analiz sonuçlarında Gray'in (1988) modelini destekleyecek bir biçimde dört faktöre ulaşılmış olsaydı, söz konusu muhasebe değerlerinin ampirik olarak test edildiğini söylemek mümkün olabilecekti. Ancak gerçekleştirilen açımlayıcı ve doğrulayıcı faktör analizi sonuçlarına göre beş faktörlü bir yapı tespit edilmiştir. Bu bağlamda, analiz sonuçlarını Gray'in (1988) muhasebe değerleri bağlamında yorumlamak mümkün gözükmektedir.

İlgili literatür incelendiğinde, Gray'in (1988) teorik olarak yapısını test eden genel olarak tutarlı olduğunu belirten çalışmalar mevcuttur (Tsakumis, 2007; Doupnik \& Riccio, 2006; Salter \& Niswander, 1995; Sudarwan \& Fogarty, 1996). Bu bağlamda çalışma, bu yönüyle söz konusu çalışmalar ile benzerlik göstermektedir.

Aynı zamanda araştırmada kullanılan ölçeğin açıklanan toplam varyans değer ise \%64,58 olarak belirlenmiştir. Bu durumda, henüz tanımlanmamış başka muhasebe değerlerinden söz edilebilir. Teorik temel yerine deneysel olarak hazırlanan veri toplama tekniği ile tanımlanmamış diğer muhasebe değerlerini tanımlamak mümkün olabilecektir.

Muhasebe Değerleri Anketi'nin belirtilen sınırlamalarını ve zayıflıklarını ele almak için geliştirilmesi ve farklı ülkelerde ve kullanıcılarda uygulanması gerekmektedir. Bu bağlamda, farklı bölgelerdeki muhasebeci ve yöneticilere muhasebe değerleri anketi uygulanıp farklılıklar değerlendirilebilir. Bu tür çalışmaların gerçekleştirilmesi, muhasebe değerleri için bir veri havuzunun geliştirilmesine katkıda bulunacak ve muhasebe değerlerinin araştırılmasına ilişkin mevcut veri eksikliğinin giderilmesine yardımcı olacaktır.

\section{Kaynakça}

Albuquerque, F., Almeida, M. C., \& Quirós, J. (2011). The Culture And The Accounting Values: An Empirical Study In View Of Portuguese Preparers. Journal Of International Business And Economics, 11(2), 16-27.

Bekci, İ., \& Bitlisli, F. (2012). Muhasebe-Kültür Değerlerinin Analizi: Muhasebe Meslek Mensupları Üzerine Bir Araştırma. Cumhuriyet Üniversitesi İ̈BF Dergisi, 13(1), 61-76.

Blodgett, J. G., Bakir, A., \& Rose, G. M. (2008). A Test of the Validity of Hofstede's Cultural Framework. Journal of Consumer Marketing, 25(6), 339-349.

Borker, D. R. (2013). Is There A Favorable Cultural Profile For IFRS?: An Examination And Extension Of Gray's Accounting Value Hypotheses. International Business \& Economics Research Journal (IBER), 12(2), 167178.

Chanchani, S., \& Willett, R. (2004). An Empirical Assessment of Gray's Accounting Value Constructs. The International Journal of Accounting(39), 125-154.

Demir, E., Saatçioğlu, Ö., \& İmrol, F. (2016). Uluslararası Dergilerde Yayımlanan Eğitim Araştırmalarının Normallik Varsayımları Açısından İncelenmesi. Curr Res Educ, 2(3), 130-148.

Doupnik, T. S., \& Riccio, E. L. (2006). The Influence of Conservatism and Secrecy on the Interpretation of verbal Probability Expressions in the Anglo and Latin Cultural Areas. The International Journal of Accounting(41), 237-261. 
M. Yücenurşen - M. Karakuş 13/1 (2021) 481-492

Durmuş, A. F., \& Güneş, R. (2017). Türkiye'deki Yeminli Mali Müşavirlerin Kültür Bazlı Muhasebe Değerlerinin Analizi. Muhasebe ve Finansman Dergisi(76), 81-98.

Gray, S. J. (1988). Towards a Theory of Cultural Influence on the Development of Accounting Systems Internationally. Abacus, 24(1), 1-15.

Hofstede, G. (1980). Culture's Consequences, International Differences in Work-Related Values. Beverly Hills: Sage Publications.

Hofstede, G. (1980). Motivation, Leadership, and Organization: Do American Theories Apply Abroad? Organizational Dynamics, 9(1), 42-63.

Hofstede, G. (2011). Dimensionalizing Cultures: The Hofstede Model in Context. Online Readings in Psychology and Culture, 2(1), 1-26.

Hofstede, G., \& Bond, M. H. (1984). Hofstede's Culture Dimensions: An Independent Validation Using Rokeach's Value Survey. Journal of Cross-Cultural Psychology, 15(4), 417-433.

Hofstede, G., \& Usunier, J.-C. (2003). Hofstede's Dimensions of Culture and their Influence on International Business Negotiations. P. N. Ghauri, \& J.-C. Usunier içinde, International Business Negotiations (s. 137154). Oxford: Elsevier.

Huettinger, M. (2008). Cultural Dimensions in Business Life: Hofstede's Indices for Latvia and Lithuania. Baltic Journal of Management, 3(3), 359-376.

Karabınar, S. (2005). Kuiltü̈ ve Muhasebe Açısından Muhasebe İklimi. Ankara: Seçkin.

Keskin, D. A., Tutar, S., \& Yazgan, K. F. (2020). Şeffaflık Raporlarının Hofstede-Gray Modeliyle Muhasebe Kültürü Açısından Karşılaştırılması: Türkiye, Nijerya, Letonya ve İngiltere Örneği. Muhasebe Bilim Dünyası Dergisi(22), 195-213.

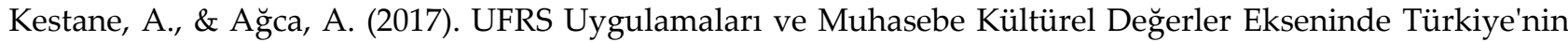
Yeri. Muhasebe Bilim Dünyası Dergisi, 19(3), 624-649.

Khlif, H. (2016). Hofstede's Cultural Dimensions in Accounting Research: A Review. Meditari Accountancy Research, 24(4), 545-573.

Merritt, A. (2000). Culture in the Cockpit: Do Hofstede's Dimensions Replicate? Journal of Cross-Cultural Psychology, 31(3), 283-301.

Mooij, M. d., \& Hofstede, G. (2010). The Hofstede Model Applications to Global Branding and Advertising Strategy and Research. International Journal of Advertising, 29(1), 85-110.

Noravesh, I., Dilami, Z. D., \& Bazaz, M. S. (2007). The Impact of Culture on Accounting: Does Gray's Model Apply to Iran? Review of Accounting and Finance, 6(3), 254-272.

Perera, H., Cummings, L., \& Chua, F. (2012). Cultural Relativity of Accounting Professionalism: Evidence from New Zealand and Samoa. dvances in Accounting, Incorporating Advances in International Accounting(28), 138-146.

Rodriguez, R. P. (2009). Three Essays on the Quantification, Validation, and Application of Gray's Accounting Values. Teksas: Yayımlanmamış Doktora Tezi.

Salter, S. B., \& Lewis, P. A. (2011). Shades of Gray: An Empirical Examination of Gray's Model of Culture and Income Measurement Practices Using 20-F Data. Advances in Accounting, Incorporating Advances in International Accounting(27), 132-142.

Salter, S. B., \& Niswander, F. (1995). Cultural Influence on the Development of Accounting Systems Internationally: A Test of Gray's (1988) Theory. Journal of International Business Studies(26), 379-397.

Saylık, A. (2019). Hofstede'nin Kültür Boyutları Ölçeğinin Türkçeye Uyarlanması; Geçerlik ve Güvenirlik Çalışması. Uluslararası Türkçe Edebiyat Kültür Ĕ̆itim Dergisi, 8(3), 1860-1881.

Schultz, J. J., \& Lopez, T. J. (2001). The Impact of National Influence on Accounting Estimates: Implications for International Accounting Standard-Setters. The International Journal of Accounting(36), 271-290. 
Soares, A. M., Farhangmehr, M., \& Shoham, A. (2007). Hofstede's Dimensions of Culture in International Marketing Studies. Journal of Business Research(60), 277-284.

Sudarwan, M., \& Fogarty, T. J. (1996). Culture and Accounting in Indonesia: An Empirical Examination. The International Journal of Accounting, 31(4), 463-481.

Tsakumis, G. T. (2007). The Influence of Culture on Accountants' Application of Financial Reporting Rules. Abacus, 43(1), 27-48.

Yaşlığlu, M. M. (2017). Sosyal Bilimlerde Faktör Analizi ve Geçerlilik: Keşfedici ve Doğrulayıcı Faktör Analizlerinin Kullanılması. Istanbul University Journal of the School of Business(46), 74-85.

EK:

Muhasebe Değerleri Anketi (Accounting Value Survey - AVS)

\begin{tabular}{|l|l|}
\hline 1 & Şüpheli durumlarda varlıklar ve kar ihtiyatlı değerlendirilmelidir. \\
\hline 2 & Özellikli varlıklar için özel amortisman yöntemleri belirlenmelidir. \\
\hline 3 & Finansal tablolar sadece hissedarlar ve yöneticilere değil aynı zamanda kamuoyuna açık olmalıdır. \\
\hline 4 & Muhasebe mesleği “kendi kendini” düzenlemelidir. \\
\hline 5 & Piyasa değeri, tarihi maliyetlere göre daha az uygundur. \\
\hline 6 & Bütün şirketlerin finansal tabloları standart formatlara sahip olmalıdır. \\
\hline 7 & Finansal tablolara yalnızca minimum miktarda ayrıntılı veri dahil edilmelidir. \\
\hline 8 & $\begin{array}{l}\text { Profesyonel muhasebeci, bir şirketin finansal durumunu ve performansını nasıl ölçecekleri konusunda en yetkili } \\
\text { kisidir. }\end{array}$ \\
\hline 9 & Tarihi maliyetler yerine piyasa değerleri kullanılmalıdır. \\
\hline 10 & Muhasebe politikaları seçildikten sonra değiştirilmemelidir. \\
\hline 11 & Yönetim ve şirket sahipleri hakkındaki bilgiler mali tablolara dahil edilmemelidir. \\
\hline 12 & Profesyonel muhasebeciler, mali tablolarda neyin sunulacağına dair en yetkili karar vericidir. \\
\hline 13 & Fiyatların yükseldiği zamanlarda FIFO yerine LIFO kullanılmalıdır. \\
\hline 14 & Mali tablolarda ayrıntılı standardizasyon seviyesi artırılmalıdır. \\
\hline 15 & Yönetim tahminleri, mali tablolara dahil edilmelidir. \\
\hline 16 & Muhasebe meslek mensupları, yüksek etik davranış standartlarını korumalıdır. \\
\hline
\end{tabular}

